\title{
TRATAMENTO JURÍDICO DADO AO VAZAMENTO DO PETRÓLEO NO CAMPO DE FRADE. ESTUDO DE CASO: (I) RESPONSABILIDADE CIVIL E A ASSINATURA DO TERMO DE AJUSTAMENTO DE CONDUTA
}

Alexandre Ricardo Machado

Professor, Consultor e Advogado em Direito do Petróleo e Gás, Mestre em Direito Ambiental, Doutorando em Direito Ambiental Internacional da Universidade Catolica de Santos. Bolsista CAPES.

Edson Ricardo Saleme

Professor Doutor, do curso de Mestrado stricto sensu da Universidade Católica de Santos. Professor da UNIP e Escola Superior do Ministério Público. Consultor do IBAMA e do MDS.

\section{Resumo}

Este artigo discutirá como foram tratados os desdobramentos jurídicos e ambientais ocasionados pelo grande vazamento de petróleo ocorrido no CAMPO DE FRADE (RJ), pela empresa americana CHEVRON Brasil, em face das autoridades nacionais. No texto se discutiráo questốes relacionadas à responsabilidade civil objetiva e suas teorias diante da extinçáo de duas açóes civis públicas propostas pelo Ministério Público Federal e de um Termo de Ajustamento de Conduta. Neste estudo se fará uma análise cronológica dos fatos que permearam os dois derramamentos de petróleo e a forma como a empresa CHEVRON Brasil lidou com o incidente, sobretudo após se firmar o referido compromisso entre ela, o Ministério Público Federal (MPF), Agência Nacional de Petróleo (ANP) e Instituto Brasileiro do Meio Ambiente (IBAMA) solucionando as duas açōes civis públicas propostas e relacionadas aos incidentes ocorridos no campo de Frade, em 2011 e 2012. O processo também desencadeou aplicação de multas pecuniárias, já recolhidas. No trabalho serão tecidas considerações relacionadas ao incidente e sua "solução" por essa fórmula jurídica e se, diante da gravidade do acidente, as medidas indicadas revelam acerto ou náo dos setores competentes.

\section{Palavras-chave}

Derrame de Petróleo; Chevron; Campo de Frade; Dano Ambiental. 


\section{Abstract}

This paper is to discuss how were treated the legal and environmental consequences caused by the large oil spill occurred in the FRADE FIELD, State of Rio de Janeiro, Brazil by the Company CHEVRON Brazil, in the face of brazilian authorities. On the text it will be discussed important decisions taken related to objective liability from the Company due to damages and the theories that have been taken into consideration for the extinction of two public civil actions filed by the Federal Public Ministry by an agreement called "Conduct Adjustment Term”. This study will make a chronological analysis of the facts that occurred on the two oil spills and how the company Chevron Brazil handled the incident, especially after be signed the undertaking between this Company, the Federal Public Ministry (MPF), National Agency Petroleum (ANP) and the Brazilian Institute of Environment and Renewable Natural Resources (IBAMA) solving the two public civil actions and proposals related to incidents in the Frade field in 2011 and 2012. The process also triggered imposition of financial penalties, already collected. On this comments shall be made considerations related to the incident and its "solution" for this legal formula and, given the severity of the accident, the indicated measures show hit or not the sectors involved.

\section{Key words}

Case Study; Oil Spill; Chevron; Frade Field; Environmental Damage.

\section{Introdução}

A incessante atividade de exploração e produção de petróleo e gás em diferentes regiōes do mundo, mantém seu avanço nas reservas encontradas no mar, conhecidas como Offshore. Atualmente representam a grande maioria das bacias sedimentares mundiais. $\mathrm{O}$ Brasil, em face da crescente intensificação de suas atividades de exploração e produção do produto, intensificou a exploração offshore após a descoberta do Pré-sal ${ }^{1}$ e da aparente dificuldade do judiciário brasileiro, no trato de questóes de cunho ambiental relacionadas ao petróleo.

Nesse sentido, de acordo com as informações do Centro Brasileiro de Infraestrutura - CBIE (2015), o Brasil é o país onde a produção marítima é a mais elevada, representando cerca de $95 \%$ do total produzido. Com a exploração do Pré-sal este índice se elevará ainda mais, criando novos riscos de acidentes ambientais com petróleo. Isso gera a necessidade de novas discussóes sobre o assunto e como será tratado pelo Judiciário brasileiro.

1 O pré-sal é uma camada de petróleo localizada em grandes profundidades, sob as águas oceânicas, abaixo de uma espessa camada de sal. 
Diante desse novo quadro importa efetivar análise mais apurada das questóes de cunho jurídico abrangidas nos processos judiciais movidos contra a Empresa Chevron, tanto no âmbito Civil - Ação Civil Pública (MPF, 2012), quanto no âmbito Criminal Denúncia (MPF, 2015b), visando elevar ainda mais tão importante discussão.

A partir da relevância do tema indaga-se: como a empresa americana CHEVRON, operadora do CAMPO DE FRADE (RJ), tratou os desdobramentos ambientais e jurídicos causados pelo vazamento de petróleo, junto as autoridades brasileiras? Como foi discutida a competência e soberania brasileira para julgamento dos processos, no que se refere ao local do acidente? E qual o papel da Responsabilidade Civil objetiva e suas teorias, com a extinção das duas Açóes Civis Públicas propostas pelo Ministério Público Federal diante do Termo de Ajustamento de Conduta?

O objetivo desse estudo consiste em apresentar uma análise cronológica dos fatos que permearam os derramamentos de petróleo e a forma como a empresa americana Chevron lidou com o incidente e com às autoridades brasileiras. Destarte, diante dos danos ambientais, serão analisadas as consequências jurídicas causadas, repercutindo-se em termos de responsabilidade civil e como isso poderia ser solucionado por meio de termo de ajustamento de conduta.

Para tanto, será apresentada uma abordagem sobre as irregularidades praticadas pela Empresa Chevron constatadas pelo Instituto Brasileiro do Meio Ambiente e dos Recursos Naturais Renováveis - IBAMA e a Agência Nacional de Petróleo, Gás Natural e Biocombustíveis - ANP, que desencadearam na aplicação de multas pecuniárias, já devidamente recolhidas ${ }^{2}$.

A metodologia ${ }^{3}$ empregada baseou-se no estudo de caso, pesquisa bibliográfica de meios impressos e eletrônicos, do inquérito, da ação civil pública, do TAC, do relatório do acidente emitido pela ANP, além dos processos decisórios de grande relevância nacional.

\section{Descrição do Fenômeno: 0 Caso Chevron no Campo de Frade}

A Chevron é uma das maiores empresas de energia do mundo, com subsidiárias em diversos países. Suas afiliadas estão presentes no Brasil desde 1915, com a comercialização de produtos derivados de petróleo com a marca Texaco, que se firmou no país como uma das maiores distribuidoras de combustíveis.

2 A Chevron Brasil já quitou todas as multas aplicadas pelo IBAMA no total de R\$54.000.000,00, tendo recolhido R \$ 42.857.010,00, com o desconto de 30\% previsto no “caput" do art. 4º, da Lei n.o 8.005, de 1990 , assim como já quitou todas as multas aplicadas pela ANP relativas ao primeiro incidente no total de $\mathrm{R}$ \$ 36.650.000,00, tendo recolhido $\mathrm{R} \$ 25.592 .000,00$ com o desconto de $30 \%$ previsto no art. $4^{\circ}$, $\$ 3^{\circ}$, da Lei n. ${ }^{\circ} 9.847$, de 1999.

3 Utilizou-se como base metodológica para o desenvolvimento da pesquisa, o modelo de estudo de caso sistematizado bibliográfico, proposto por Marcelo Lamy (2011). 
Em 1997, a empresa instalou seu escritório de exploração e produção de petróleo no Rio de Janeiro, seguindo a decisão do governo brasileiro de abrir o setor a investimentos privados. Hoje, a Chevron Brasil Ltda. tem participação em três projetos de exploração em águas profundas no Brasil: 51,74\% no Campo de Frade, onde opera desde 2009; $37,5 \%$ em Papa-Terra (não operadora) e 30\% em Maromba (não operadora) - todos na Bacia de Campos (ANP, 2007).

O Campo de Frade, localiza-se na Bacia de Campos, Estado do Rio de Janeiro, confrontando-se a leste com o Campo de Roncador, sob concessão da Petrobras. A distância até o litoral do Município de Campos dos Goytacazes é de aproximadamente 113 $\mathrm{km}$. A lâmina d'água ${ }^{4}$ é em torno de 1.100 metros e a área atual do campo é de $154 \mathrm{~km}$, dentro do território marítimo brasileiro, mais precisamente dentro da Zona Econômica Exclusiva Brasileira.

Descoberto em dezembro de 1986, pela Petrobrás, e declarado comercial pela Agência Nacional de Petróleo (ANP), em 1998. O desenvolvimento da área de Frade é atualmente realizado por um consórcio de empresas formado pela Petrobras E\&P, que detém 30\% de participação, pela Frade Japão Petróleo Ltda., com 18,3\% e pela Chevron Brasil Ltda., com 51,7\%, que opera o campo em nome de suas parceiras, através do Contrato de Concessão 48000.0038969720 (ANP, 2007).

A atividade de produçáo do campo envolve o FPSO Frade 5 (Floating Production, Storage and Offloading) está regularmente licenciada pelo IBAMA, por meio da licença de operação no 845/2009 (MMA, 2012).

O incidente, iniciado no dia 07 de novembro de 2011, com um "kick" 'durante a perfuração pela Unidade Marítima de Perfuração Transocean SEDCO 706, do poço MUP1-P-ST2-N545D (9FR50DPRJS) no campo de Frade, resultou em vazamento de óleo a partir de fissuras no leito marinho (ANP, 2012).

Vale lembrar que a empresa assumiu um risco ao explorar petróleo em alto mar. Este somente tornou-se viável em face aos avanços da tecnologia de perfuração petrolífera. Porém, mesmo em condiçóes críticas, decidiu explorar. No caso vertente, a resistência das paredes da própria rocha que compunha o poço não se manteve incólume. A empresa não foi capaz de interpretar corretamente a geologia e a fluidodinâmica do local, apesar de já haver perfurado 62 poços no Campo de Frade, ocasionando o "kick", evento iniciador que culminou com a exsudação do óleo para o mar (ANP, 2012).

4 Profundidade vertical entre o leito oceânico e a superfície do mar.

5 Unidade Flutuante de Produção, Armazenamento e Transferência é um tipo de navio utilizado pela indústria petrolífera para a explotação (produção), armazenamento petróleo e/ou gás natural e escoamento da produção.

6 "Kick" é quando entram fluidos no poço, não necessariamente chegando à superfície, mas acarretando risco. 
Destaca-se ainda que o Estudo de Impacto Ambiental - EIA, obtido pela própria Chevron, especificava como estratégia de gerenciamento de risco a identificação de perigos e avaliação de implementação de medidas de controle específicas ao Projeto do Campo de Frade. Isso permitiria, em tese, que os riscos fossem conhecidos, mensurados, mitigados e reduzidos ao mínimo (IBAMA, 2006).

Conforme relatório final do incidente realizado pela ANP (2012), o acidente poderia ter sido evitado, caso a empresa tivesse conduzido suas operaçóes em plena aderência à regulamentação, em conformidade com as boas práticas da indústria do petróleo e com seu próprio manual de procedimentos, onde a empresa não foi capaz de interpretar corretamente a geologia e a fluidodinâmica local.

\subsection{O Primeiro Vazamento}

Em 7 de novembro de 2011, a equipe da plataforma submersível SEDCO 706, de propriedade da empresa Transocean Brasil Ltda., identificou a ocorrência de kick de óleo no poço MUP1, que estava sendo perfurado no Campo de Frade pela concessionária Chevron Brasil Upstream Frade Ltda. O equipamento de segurança BOP - Blowout Preventer $^{7}$ foi acionado visando o fechamento do poço, o qual, como veremos adiante, não foi totalmente fechado por ineficiência da Chevron. A partir daí foi iniciado o procedimento de circulação do fluido invasor ${ }^{8}$ (ANP, 2012).

No dia 08 de novembro de 2011, a PETROBRÁS comunicou a presença de mancha de óleo ${ }^{9}$ localizada entre os Campos de Frade e Roncador. Iniciada busca para identificação de um possível ponto de derramamento com utilização de ROV - Remotely Operated Vehicle $^{10}$, foram localizadas sete fissuras, a maior medindo cerca de 300 metros de extensão (ANP, 2012).

Em 9 de novembro de 2011, a Chevron comunicou oficialmente o acidente no Campo de Frade e informou o início dos procedimentos previstos no Plano de Emergência Individual, previsto na Resolução CONAMA no 398, de 2008 (ANP, 2012; CONAMA, 2008).

A ANP e o IBAMA, a partir do dia 10 de novembro de 2011, passara a acompanhar o acidente no próprio Centro de Comando da concessionária Chevron. Ocasião em que se deliberou, em reuniáo, o abandono do poço fissurado.

7 BOP é um conjunto de válvulas de segurança usada para selar, controlar e monitorar os poços de $\mathrm{P} \& \mathrm{G}$.

8 Elevação do peso da lama para conter a pressão e realizar a sua cimentação.

9 O petróleo vazou por meio do poço que estava sendo perfurado, migrou para as rochas por meio de fissuras nas paredes do poço e aflorou no fundo do mar, atingindo a superfície da água e formando as grandes manchas - óleo.

10 ROV-Remotely Operated Vehicle - sigla em inglês para veículo operado remotamente. 
No dia 12 de novembro de 2011, o IBAMA conseguiu realizar o sobrevoo na área afetada com comparação com imagens RADARSAT ${ }^{11}$, tendo a empresa estimado que a área afetada pela mancha de óleo estava em torno de $120 \mathrm{~km}^{2}$ e o volume de óleo no mar estava entre 64 e $104 \mathrm{~m}^{3}$, o equivalente a cerca de 440 a 720 barris de petróleo. Essas informaçôes foram consideradas compatíveis com as imagens de satélite, a partir de interpretação dada por especialistas da Marinha (PORTAL BRASIL, 2012).

Em 14 de novembro de 2011, a empresa estimou que a área da mancha já estava em $163 \mathrm{~km}^{2}$, derivando na direção Sul-Sudeste, ou seja, se afastando da costa. Já o volume de óleo foi estimado entre 83 e $140 \mathrm{~m}^{3}$ (570 a 970 barris), inferido a partir de imagens de satélite. A interpretação dos dados que resultou na quantificação da área afetada foi, novamente, corroborada pela Marinha do Brasil.

No dia 15 de novembro de 2011, a ANP detectou, em ação fiscalizatória, que os equipamentos necessários ao fiel cumprimento do plano (devidamente aprovado) de abandono de poço, não se encontravam na posse da concessionária Chevron (ANP, 2012; IBAMA, 2014).

Ressalte-se, aqui, que a empresa Halliburton, contratada pela Chevron para realizar a elevaçáo do peso da lama para conter a pressáo do poço e realizar a sua cimentaçáo, náo conseguiu deter o derramamento de óleo no mar, piorando a situação. A ANP calculou um derramamento médio de 200 a 300 barris por dia, no período de 08/11 a 15/11, tendo vazado na média aproximadamente 3.000 (três mil) barris de petróleo (ANP, 2012).

O IBAMA, em 21 de novembro de 2011, autuou a empresa Chevron para pagamento da multa administrativa de $\mathrm{R} \$ 50.000 .000,00$ (cinquenta milhóes de reais), com base nos artigos 70 e 72, inciso II, da Lei Federal no 9.605, de 1998, artigo 17 da Lei Federal no 9.966, de 2000 e artigo 36 do Decreto Federal no 4.136, de 2002, por ter a referida empresa "dado causa a descarga (derramamento) de petróleo na plataforma SEDCO 706, durante perfuração do poço MUP1, no Campo de Frade, na Bacia de Campos” (IBAMA, 2012).

A ANP, a seu turno, instaurou processos administrativos para investigação das causas do acidente e das infraçóes cometidas pela demandada Chevron. A concessionária, nesse contexto, foi autuada duas vezes, além da autuação do IBAMA. Primeiro, por descumprir o plano de abandono do poço, já que não dispunha dos equipamentos necessários à execução do plano que ela mesma havia submetido à Agência Nacional de Petróleo. Segundo, por omitir informaçóes ao órgão regulador, ao entregar imagens editadas das filmagens feitas por veículo remoto nos pontos de derramamento.

Além disso, a Chevron teve suspensas suas atividades de perfuração no Brasil. A medida não alcança as atividades necessárias ao abandono definitivo do poço que deu origem ao derramamento nem restauração das suas condições de segurança. A decisão baseou-se nas

11 Satélite de observação da Terra, controlado pelo Canadá. 
análises e observaçôes técnicas da Agência, que verificaram negligência da concessionária na apuração de dado fundamental para a perfuração de poços e na elaboração e execução de cronograma de abandono, além de falta de maior atenção às melhores práticas da indústria.

A ANP também rejeitou, naquela oportunidade, o pedido da companhia para perfurar um novo poço em Frade em direçáo à camada do Pré-sal em razão dos ríscos de natureza semelhante agravados pela maior profundidade.

\subsection{Segundo Vazamento}

Em 15 de março de 2012, a ANP (2012, p.1-2) informou, em nota oficial, "que foi registrado um novo vazamento de petróleo na mesma regiáo onde a petroleira americana Chevron já tinha um derramamento, no Campo de Frade, na Bacia de Campos (RJ), em novembro do ano passado". Ressalte-se, por oportuno e necessário, que na referida nota oficial emitida pela ANP, consta que "a Chevron foi autuada novamente por não ter atendido notificação da ANP para apresentar medidas necessárias que evitassem novas exsudaçóes na área onde vazou petróleo do Campo de Frade”.

Os técnicos da ANP constataram, por meio de filmagens submarinas, cinco pontos ao longo de uma fissura de 800 metros no solo marinho, na concessão do Frade, de onde se observava o aparecimento de gotículas de óleo, em uma vazão reduzida.

Vale considerar, ainda, que através de a nota oficial, divulgada em 20 de março de 2012, a ANP (2012, p.3) informou que "foram identificados, na última semana (compreendida entre 12 e 18 de março) novos pontos de vazamento de óleo no solo marinho, na concessão de Frade", de onde não é preciso raciocínio elaborado para concluir que restou provado que o acidente que ocasionou o primeiro vazamento resultou em danos mais sérios e ainda de extensão não mensurada ou totalmente conhecida, mas, com certeza, grave.”

Assim, no dia 15 de março de 2012, um novo derramamento ocorreu no Campo de Frade. Esta vez outra fratura marítima que ultrapassou 800 metros gerou o desastre. Esta nova ocorrência, visceralmente associada às condiçóes adversas criadas pelo primeiro acidente, além de agravar, sobremodo, as nefastas consequências ambientais já relatadas, implicaram no aumento dos danos causados à rocha reservatório na sua condição de patrimônio da Uniáo.

\section{Jurisdição para Julgamento e Processo}

No estudo em questão há de se afirmar que a jazida de petróleo ${ }^{12}$ consistente no Campo de Frade e levando em consideração todos os poços perfurados é de propriedade

12 O sistema geológico de um campo de petróleo é composto pelas rochas reservatório, rochas geradoras e rochas selantes. Fala-se em sistema porque se não houver sincronismo geológico na formação destes 
da Uniấo, nos termos da Constituição Federal, mais especificamente em seus incisos $\mathrm{V}$ e IX, do artigo $20^{13}$.

O Estado Brasileiro, sob a dimensão internacional, é o proprietário das jazidas de petróleo situadas no subsolo marinho compreendido dentro dos $370 \mathrm{~km}$ - 200 milhas náuticas - contados da linha base do litoral brasileiro. Na condição jurídica de proprietário das jazidas de petróleo, é que o Estado Brasileiro possui o inarredável e inalienável direito de tomar todas as medidas jurídicas, judiciais, jurisdicionais e legislativas no escopo de proteger não só os bens objeto da predita propriedade como o próprio exercício deste direito (BRASIL, 1993; MARTINS, 2015).

Nesse sentido, o território nacional é constituído pelos seguintes elementos: parte continental, parte marítima, sendo que esta última, também conhecida por águas territoriais ou águas jurisdicionais, ais quais abrange o Mar Territorial, a Zona Econômica Exclusiva e a Plataforma Continental ${ }^{14}$.

Sabe-se que o derramamento de óleo ocorreu na Zona Econômica Exclusiva brasileira, ou seja, dentro da área abrangida pelo território marítimo brasileiro sobre a qual o Estado costeiro exerce jurisdição relativa à exploração, aproveitamento, conservação e gestão de recursos naturais vivos ou mortos. O limite da ZEE foi estabelecido em 1982, pela Convenção das Naçôes Unidas sobre direitos do mar, aprovada pelo Congresso Nacional pelo Decreto Legislativo no 5 , de 1987, e posta em vigor em junho de 1995, mediante o decreto no 1.530 (BRASIL,1995; BRASIL,1987).

Assim, verifica-se que, a gestão, uso e exploração dos oceanos e mares é matéria eminentemente de Direito Internacional, razão pela qual sua regulamentação jurídica deu-se por Convenção Internacional.

Inobstante as inúmeras tentativas da empresa Chevron levar o caso para a jurisdição internacional, manteve-se inarredável a competência para processo e julgamento do

três tipos de rochas o local não será um optimum para a produção de petróleo. Pela conjunção de fatores naturais, o petróleo migra das rochas geradoras para as reservatórios, onde fica retido. Entre as rochas reservatório e o leito oceânico existe a rocha selante, pois do contrário, o hidrocarboneto vazaria naturalmente para o leito do oceano, atingindo a lamina d'água correspondente. O conceito de produção é extremamente importante, pois o petróleo ainda não produzido (incrustrado na rocha) é, precisamente, o que forma o patrimônio nacional sob propriedade e administração da União Federal ex vi constitutiones. O petróleo no poço ou dentro dos tanques de armazenamento no navio sonda ou em navios auxiliares é de propriedade da concessionária ex vi contractus.

13 Art. 20. São bens da União: [...] V - Os recursos naturais da plataforma continental e da zona econômica exclusiva; IX - Os recursos minerais, inclusive os do subsolo;

14 O território marítimo brasileiro abrange as zonas marítimas sob soberania ou jurisdição nacional, nomeadamente, as águas interiores, o mar territorial (MT), a zona contígua (ZC), a zona econômica exclusiva (ZEE) e a plataforma continental (PC). A CNUDM III - Conferência da ONU sobre o Direito do Mar - estabeleceu limites dos espaços marítimos, estipulando 12 milhas para o Mar Territorial, 188 milhas de Zona Econômica Exclusiva, delimitando ainda a Plataforma Continental e a Zona Contígua (24 milhas). 
incidente em questão ser da Justiça Federal, conforme estabelece o artigo 109, inciso III da CF, de $1988^{15}$, que afirma serem as causas fundadas em tratados ou contratos firmados entre a união e estado estrangeiro ou organismo internacional, da competência da justiça federal. Assim, a Convençáo do Direito sobre o Mar amolda-se à espécie normativa exigida no inciso mencionado, vez que se trata de compromisso jurídico de Direito Internacional firmado entre a União (Brasil) e um Organismo Internacional, qual seja a organização das Naçóes Unidas (ONU).

Apenas a título de argumentação, não fossem os conceitos estabelecidos pela Convenção Internacional de Mar Territorial, Zona Econômica Exclusiva e Plataforma Continental com todas as suas implicações jurídicas e fáticas, o acidente envolvendo a empresa Chevron está, in statu assertioni, fundada em tratado internacional. Este elemento é fundamental para se determinar a competência da Justiça Federal, o que de fato se consumou, pois, ambas as ações civis públicas ali tramitaram.

\section{Analise dos Danos Ambientais e sua Extensão no Processo}

Os mares e os oceanos são fontes abundantes de recursos biológicos e naturais comparáveis ou até mesmo superiores às florestas tropicais - razão pela qual o território marítimo brasileiro é denominado "Amazônia Azul"16 - e são essenciais para determinar o clima da Terra, sendo também responsáveis pela constante reciclagem de produtos químicos, nutrientes e água. Não bastasse isso, são fontes importantíssimas de alimentos e emprego, além de se constituírem em vias naturais de comunicação, transporte e comércio (MARTINS, 2015).

Os derramamentos provenientes de dutos e navios, oriundos de um acidente ou durante operaçóes rotineiras como carga e descarga, são menos frequentes, porém recebem maior apelo para seu combate, dada a grande visibilidade e consequências trágicas que a poluição aguda pode provocar sobre os ecossistemas atingidos.

15 Art. 109._Aos juízes federais compete processar e julgar:

I - As causas em que a Uniāo, entidade autárquica ou empresa pública federal forem interessadas na condição de autoras, rés, assistentes ou oponentes, exceto [...];

16 A área oceânica brasileira é chamada de Amazônia Azul porque é quase tão grande quanto a floresta amazônica, que cobre boa parte do nosso país. São $4.489 .919 \mathrm{~km}^{2}$ de área, formada por mais de três milhóes de $\mathrm{km}^{2}$ de Zona Econômica Exclusiva (ZEE) e mais 950 mil km² de plataforma continental. Juntos, esses espaços marítimos correspondem a 52\% do tamanho das terras continentais. A porção de mar correspondente a Amazônia Azul foi declarada território brasileiro em 1982, na Convenção das Naçóes Unidas sobre os direitos do mar (CNUDM) e ratificada pelo Brasil, apesar de nem todos os países terem assinado a convenção ainda - o que não diminui a importância dessa área para o país. A área poderá ser ampliada para 4,4 milhōes de quilômetros quadrados em face da reivindicação brasileira perante a Comissão de Limites das Naçóes Unidas. É proposto prolongar a plataforma continental do Brasil em 900 mil quilômetros quadrados de solo e subsolo marinhos, que o país poderá explorar. 
Analisar os riscos envolvidos é uma das estratégias técnicas mais utilizadas para avaliar os impactos ambientais que um empreendimento como a prospecção e extração de petróleo em águas marítimas profundas pode causar, como consequência de acidentes. Constatar tais riscos consiste em usar um conjunto de técnicas ou métodos aplicados a uma atividade proposta ou existente com o objetivo de se identificar e avaliar o risco à própria empresa, à população vizinha ou ao meio ambiente, gerado pela atividade em questão, em termos de frequência e consequências, e propor medidas de redução da vulnerabilidade com critérios de aceitação previamente estabelecidos (LEITE, 2012).

De acordo com o Estudo de Impacto Ambiental - EIA II, apresentado pela Chevron a empresa realizou ao longo de 2005 e no primeiro semestre de 2006 investigaçóes geotécnicas e da fauna bentônica no local de instalação da unidade FPSO e de todos os equipamentos do sistema submarino, e ao longo da rota inicialmente planejada para instalação do gasoduto de ligação da FPSO ao ponto de conexão com o gasoduto de Roncador. Estas investigaçóes tiveram objetivo de averiguar as condiçóes do assoalho marinho, mitigando riscos de instabilidade geológica e, consequentemente, assegurar que a ancoragem da FPSO e dos equipamentos ocorram de forma segura, evitando riscos com os equipamentos assentados no solo marinho (IBAMA, 2007).

O dano causado era previsível e até previsto, em função da incapacidade da empresa de conter um muito provável derramamento. Isso devido à mobilização de recursos humanos e materiais a serviço da empresa era insuficiente, desde o início das operaçóes, sobretudo em face de contingências previsíveis como a que acarretou o desastre no Campo de Frade.

Sob este aspecto, a empresa não pode alegar que desconhecia os riscos de sua atividade e nem afirmar, como afiançou o seu representante para a América Latina e África, Alki Moshiri (DPF, 2011, p.1), que a "mãe natureza é complicada” e culpar a complexa geologia do Campo de Frade, por ela bem conhecida desde o início de 2009.

De acordo com o Relatório Final da ANP (2012), o erro de interpretação da geologia e da fluidodinâmica do reservatório por parte da Chevron, principalmente no que se refere aos efeitos da injeção de água por ela realizada no Campo de Frade, levou a uma estimativa incorreta no modelo de pressão do reservatório N560 na região onde ocorreu o kick. A pressão equivocadamente prevista pela empresa era de $3.700 \mathrm{psi}(9,4 \mathrm{ppg})$, conquanto, segundo os cálculos da ANP, situava-se entre 4.003psi (10,16ppg) e 4.176psi (10,6ppg).

Neste contexto de equívocos praticados pela Chevron, o Professor David Man Wai Zee (DPF, 2011, p.2), consignou que "a vistoria da área demonstrou que uma extensa mancha de óleo foi espalhada pelas ondas e pelos ventos em função de sua forma alongada e estriada. Em outros locais, a mancha apresentava, em alguns pontos, formato elíptico indicando assim uma reduzida taxa de dispersão". Observe-se que este detalhe garantiria 
um trabalho de coleta do óleo derramado (logo deixado de lado pela Chevron), em vez de espalhá-lo, o que diminuiria em muito os danos ambientais.

Restou, constatado, também, por David Zee (DPF, 2011, p.3), que “...a extensão do espalhamento da mancha de óleo foi devido à falta de capacidade de detecção rápida do vazamento do óleo no leito marinho, decorrente da perfuração do poço e piora das condiçóes de espalhamento e por conseguinte alastramento dos impactos ambientais ao dispersar o óleo mecanicamente".

E ainda, corroborando a ausência de açóes preventivas, por parte da Chevron, na minimização dos danos ambientais, Fernando Augusto Galheigo (DPF, 2011, p.5) concluiu que "a dispersão superficial do óleo observada no Campo de Frade está diretamente relacionada com o volume total de óleo vazado, e este por sua vez apresenta relação direta com o descontrole da situação que ocasionou seu lançamento no mar". Desta maneira, considerando que o vazamento foi detectado inicialmente no dia 8 de novembro e até a data do sobrevoo (12/11) o poço não havia sido controlado, "é possível afirmar que a extensão da mancha observada na superfície do mar é sim decorrente da ausência de controle imediato da situação" (DPF, 2011, p.6) ${ }^{17}$.

Aqui cabe uma ressalva, o Ministério Público Federal - MPF ofereceu denúncia contra as Empresas Chevron, Transocean, e mais dezessete pessoas físicas.

Na denúncia criminal referida segundo o MPF (2012, p. 12), o dano ambiental estaria demonstrado nos laudos elaborados por David Man Wai Zee e Fernando Augusto Galheigo, bem como nos estudos elaborados pelo IBAMA em conjunto com a Marinha do Brasil, ANP e do próprio estudo de impacto ambiental apresentado pela Chevron. Entretanto, de acordo com o Juiz Federal Marcelo Luzio Marques Araújo em sua sentença, a denúncia esbarrou em um obstáculo invencível: "a não realização do fato descrito como crime”. A poluição causada pelo vazamento do óleo não chegou a ponto de concretizar os eventos danosos elencados pelo art. 54, caput, da Lei n. 9.605, de 1998 (BRASIL, 2012, p. 22; BRASIL, 1998).

Assim, segundo as palavras do Juiz Federal na sentença, os pareceres dos peritos nomeados ad hoc pelo Delegado de Polícia Federal Fábio Scliar, "pecam pela precariedade da análise técnica. São especulações, como já se disse, firmadas apenas pela visão proporcionada pelo sobrevoo na área oceânica, atingida pelo óleo vazado para o mar, e por

17 Peritos nomeados ad hoc pelo Delegado de Polícia Federal Fábio Scliar. Professor Doutor David Man Wai Zee, da Faculdade de Oceanografia da UERJ e o Oceanógrafo e Analista Ambiental Fernando Augusto Galheigo, onde suas conclusóes foram citadas na Denúncia que tramita junto a Justiça Federal - 10ª Vara Federal Criminal do Rio de Janeiro/RJ, Processo no 0490545-96.2011.4.02.5101 (2011.51.01.4905457), tendo como réu a Chevron Brasil Petróleo Ltda e mais dezessete pessoas físicas, dentre gestoras, empregados e colaboradores das pessoas jurídicas. 
estudos teóricos acerca dos efeitos da poluição por petróleo no meio ambiente feitos antes do acidente e sem relaçáo com ele" (BRASIL, 2012, p. 23).

Ainda nas palavras do Juiz Federal: "Por outro lado, os autos deste processo contam com o Laudo Técnico que o Núcleo de Criminalística da Polícia Federal incumbiu aos Peritos Criminais para dar respostas às questóes suscitadas pelo Delegado de Polícia Federal Fábio Scliar, que, desta vez, foi municiado de informaçóes realmente precisas acerca das repercussóes do incidente sobre meio ambiente" (BRASIL, 2012, p. 24).

E o Juiz Federal conclui em sua decisão: "Em resumo, pode-se afirmar, com carradas de certeza, que a magnitude do vazamento de óleo não foi capaz, certamente por ter ocorrido em alto mar, de causar poluição ambiental penalmente relevante (...) Conclusão: falta, assim, a prova da materialidade indispensável para a aceitação da Denúncia. Também por esse motivo, é de ser rejeitada a acusação por conta de uma suposta, mas não existente, poluição ambiental penalmente relevante” (BRASIL, 2012, p. 27).

O MPF recorreu da decisão, que foi distribuída para 1a Turma Especializada do Tribunal Regional Federal da 2a regiāo, tendo como relator o Juiz Federal convocado Marcello Ferreira de Souza Granado. O julgamento do recurso, marcado para 14 de agosto de 2013, foi adiado em virtude do pedido de vista do Desembargador Paulo Espirito Santo. Ainda não há data para a retomada do julgamento.

\section{Responsabilidade Civil e suas Teorias}

A responsabilidade civil é um instituto altamente dinâmico e flexível, que vive em mudanças constantes, sempre se transformando para atender às necessidades sociais que surgem.

A tendência na sociedade, nos últimos anos, está no sentido de não deixar nenhuma vítima de dano sem reparação. Isso reflete diretamente no instituto da responsabilidade civil, uma vez que tem proporcionado um fenômeno de expansão dos danos suscetíveis de indenização.

A ideia de responsabilidade civil está relacionada diretamente ao conceito de não prejudicar outro. A responsabilidade pode ser definida como a aplicaçáo de medidas que obriguem alguém a reparar o dano causado a outrem em razão de sua ação ou omissão.

Segundo Rui Stoco (2013, p.114) “a noção da responsabilidade pode ser haurida da própria origem da palavra, que vem do latim respondere, responder a alguma coisa, ou seja, a necessidade que existe de responsabilizar alguém pelos seus atos danosos”. Da mesma forma completa "essa imposição estabelecida pelo meio social regrado, através dos integrantes da sociedade humana, de impor a todos o dever de responder por seus atos, traduz a própria noção de justiça existente no grupo social estratificado”. 
Em seu sentido etimológico e também no sentido jurídico, a responsabilidade civil está atrelada a ideia de contraprestação, encargo e obrigação. Entretanto é importante distinguir a obrigação da responsabilidade. A obrigação é sempre um dever jurídico originário; responsabilidade é um dever jurídico sucessivo consequente à violação do primeiro (CAVALIERI FILHO, 2014, p. 3).

Frise-se que a Responsabilidade Civil tem como prioridade, ainda nos tempos hodiernos, o princípio romano denominado restitutio in integrum (princípio da restituição integral). Tal premissa, aliás, antecipe-se, justifica o contido no art. 944, do Código Civil ${ }^{18}$ brasileiro (BRASIL, 2002).

A responsabilidade civil costuma ser classificada pela doutrina em razão da culpa e quanto a natureza jurídica da norma violada. Quanto ao primeiro critério a responsabilidade é dividida em objetiva e subjetiva. Em razão do segundo critério ela pode ser dividida em responsabilidade contratual e extracontratual (VENOSA, 2015).

Tendo em vista o tema tratado no presente estudo, no que se refere a reponsabilidade da empresa Chevron pelo vazamento estimado pela ANP em 3,7 mil barris de óleo em novembro de 2011, e em março de 2012, quando ocorreram novos vazamento no Campo de Frade, daremos enfoque apenas na teoria sobre a Responsabilidade Civil Objetiva, abarcada pelo direito ambiental (PASSOS DE FREITAS, 2012), visando pontuar a problemática jurídica causada pelo incidente ambiental.

\subsection{Teoria Objetiva ou Teoria do Risco}

Conforme a melhor doutrina, há de se confirmar que toda manifestação da atividade do homem traz em si a responsabilidade civil diante da coletividade existente.

Inicialmente surge a noção de culpa (LIMA, 1998), que, com o tempo sofreu constantes modificaçóes na sua aplicação, ao passo que a jurisprudência, atendendo as necessidades prementes da vida social, ampliou o seu conceito, até chegar o momento das noçóes de risco e a garantia ganhar força para substituí-la ${ }^{19}$.

Nesse contexto, surge a responsabilidade objetiva, também chamada de responsabilidade pelo risco, que descartava a existência de culpa, sustentando para possível reparação apenas o nexo causal.

Segundo Venosa (2015, p. 36), "sob esse prisma, quem, com sua atividade, cria um risco deve suportar o prejuízo que sua conduta acarreta, ainda porque essa atividade de risco lhe proporciona um benefício".

18 Art. 944. “A indenização mede-se pela extensão do dano. Parágrafo único. Se houver excessiva desproporção entre a gravidade da culpa e o dano, poderá o juiz reduzir, equitativamente, a indenização".

19 Segundo Lima: "Dentro do critério da responsabilidade fundada na culpa não era possível resolver um sem-número de casos, que a civilização moderna criara ou agravara...” 
Para o professor Paulo Alonso (2000, p.12) salienta que "a objetivação da responsabilidade civil, que tem como princípio a ideia de que todo risco deve ser garantido, desvinculou a obrigação de reparação do dano sofrido da ideia de culpa, baseando-se no risco, ante a dificuldade de obtenção da sua prova, pelo lesado, para obter a reparação".

Em relação as situaçóes dos empreendedores de responderem pelos riscos e desvantagens, existem posicionamentos diferentes, sustentando uns, o risco proveito pela existência do lucro, e outros o risco criado, oriundo da atividade criadora do risco (ALONSO, 2000; PASSOS DE FREITAS, 2012).

No que se refere atividades de exploração de petróleo, há de se afirmar que a Constituição Federal de 1988 garante a livre iniciativa para a exploração da atividade econômica, em harmonização com uma série de princípios (art. 170) ${ }^{20}$, onde uma das características principais da atividade econômica, reiterando, é a criação de riscos. Assim, do ponto de vista do dever de indenizar, a responsabilidade civil da Empresa Chevron é objetiva, oriunda do risco integral da atividade econômica exercida (PADILHA, 2010, PASSOS DE FREITAS, 2012).

$\mathrm{O}$ art. 225, $\$ 2^{\circ} \mathrm{da} \mathrm{CF}$, de 1988 impóe àquele que explore recursos minerais a obrigação de recuperar o meio ambiente degradado, não condicionando essa obrigaçáo à apuraçáo de culpa. Aduz, ainda o art. $225, \$ 3^{\circ}$, que as condutas e atividades consideradas lesivas ao meio ambiente sujeitarão os infratores, pessoas físicas ou jurídicas, a sançóes penais e administrativas, independentemente da obrigação de reparar os danos causados (MACHADO, 2015; MILARÈ, 2015; PADILHA, 2010).

Assim, é o poluidor obrigado, independentemente da existência de culpa, a indenizar ou reparar os danos causados ao meio ambiente e a terceiros, afetados por sua atividade ${ }^{21}$.

Pela teoria do risco da atividade, seu mero exercício envolve responsabilidade. Acolhendo essa teoria, o Código Civil de 2002 dispôe que "haverá obrigação de reparar o dano, independentemente de culpa, nos casos especificados em lei, ou quando a atividade normalmente desenvolvida pelo autor do dano implicar, por sua natureza, riscos para os direitos de outrem ${ }^{22}$.

20 Art. 170. [...] : I - soberania nacional; II - propriedade privada; III - funçáo social da propriedade; IV - livre concorrência; V - defesa do consumidor; VI - defesa do meio ambiente, inclusive mediante tratamento diferenciado conforme o impacto ambiental dos produtos e serviços e de seus processos de elaboraçáo e prestação; VII - redução das desigualdades regionais e sociais; VIII - busca do pleno emprego; IX - tratamento favorecido para as empresas de pequeno porte constituídas sob as leis brasileiras e que tenham sua sede e administração no País. Parágrafo único. É assegurado a todos o livre exercício de qualquer atividade econômica, independentemente de autorizaçáo de órgãos públicos, salvo nos casos previstos em lei.

21 Lei no 6.938, art. $14, \$ 1^{\circ}$.

22 CC, de 2002, art. 927, parágrafo único. 
Com o fito de ampliar a discussão, é oportuno frisar, entretanto, que existe forte divergência na doutrina jus ambientalista a respeito da aplicação das teorias que fundamentam e dão extensão à responsabilização objetiva do infrator em matéria ambiental.

Segundo Annelise Monteiro Steigleder (2010, p.325), “...de um lado a teoria do risco integral, mediante a qual todo e qualquer risco conexo ao empreendimento deverá ser integralmente internalizado pelo processo produtivo; e, de outro, a teoria do risco criado, a qual procura vislumbrar, dentre todos os fatores de risco, apenas aquele que, por apresentar periculosidade, é efetivamente apto a gerar as situaçóes lesivas, para fins de imposição de responsabilidade".

Nesse passo, tem-se que na sistemática do risco integral, a responsabilidade objetiva do ofensor pelo dano ambiental pressupóe o simples exercício de uma atividade empresarial que acarrete riscos de prejuízos ao meio ambiente, independentemente de essa atividade ser ou não considerada perigosa.

Ao justificar o posicionamento, Steigleder (2010, p. 332) anota que "imputar a responsabilização civil apenas àquele que exerce atividade "perigosa" redundaria numa "interpretação" incompatível "com o objetivo posto na Constituição de proteger o meio ambiente e combater a poluição em todas as suas formas”.

Corroborando com esse entendimento, tem-se da mesma forma Paulo Afonso Leme Machado (2015), Edis Milaré (2015), Gilberto Passos de Freitas e Wladimir Passos de Freitas (2012).

Assim, no contexto da Responsabilidade Civil Objetiva da Chevron, "mitigada" com a assinatura do Termo de Ajustamento de Conduta, que implicou em "medidas preventivas e de precaução, previstas e estabelecidas pela ANP e pelo IBAMA" a CHEVRON BRASIL se "obrigou" a prover, nos termos do Compromisso, a título de compensação socioambiental, de que natureza for, o montante de R\$95.160.000,00 (noventa e cinco milhóes, cento e sessenta mil reais) (MPF, 2013). Não podemos deixar de questionar, a eficácia na questão da aplicação de medidas de cunho "pecuniário" ainda que a título de apresentação de projetos com cunho de compensação ambiental, ser a medida mais eficiente para inibir práticas lesivas ao meio ambiente.

\subsection{Termo de Ajustamento de Conduta - TAC}

O Termo de Ajustamento de Conduta (TAC) surgiu no ordenamento jurídico como um meio alternativo de resolução de conflitos no âmbito dos direitos coletivos, ao estabelecer a possibilidade de efetivaçáo extrajudicial da tutela de referidos direitos, entre eles o ambiental, o que, além de contribuir para desafogar a máquina judiciária, evita a demanda de tempo em submeter a questão ao aparelho judiciário. 
Delineado na ordem jurídica pátria fundamentalmente pelo parágrafo $6^{\circ}$ do artigo $5^{\circ}$ da Lei de Ação Civil Pública (Lei n . 7.347/1985), o TAC pode ser conceituado, nos dizeres de Geisa de Assis Rodrigues (2002, p.297), como “...uma forma de solução extrajudicial de conflitos promovida por órgãos públicos, tendo como objeto a adequação do agir de um violador ou potencial violador de um direito transindividual (direito difuso, coletivo ou individual homogêneo) às exigências legais, valendo como título executivo extrajudicial”.

O compromisso de ajustamento de conduta é um instrumento utilizado como forma de solucionar os problemas resultantes de práticas ilícitas, neste caso o dano Ambiental, evitando que o Poder Judiciário tenha de intervir sempre que ocorrerem degradaçóes (MILARÈ, 2006).

Constatado o dano ambiental, e surgindo a possibilidade de seu causador pretender reparar o dano, ou, ainda, ajustar-se de modo a evitar a sua ocorrência ou a sua persistência, a solução consensual é forma de se evitar a propositura de medida judicial.

No tocante à natureza jurídica do termo de ajustamento de conduta, podem-se agrupar as posiçóes doutrinárias sobre o tema basicamente nas que enquadram o compromisso de ajustamento como transação bilateral, outra como acordo em sentido estrito e a que concebe o instrumento como ato administrativo (VIÉGAS, PINTO \& GARZON, 2014).

De acordo com Rodrigo Fernandes (2008, p.56-78), após discorrer extensivamente sobre as correntes de pensamento existentes em torno dessa modalidade de compromisso, conclui que o ajustamento de conduta "responde satisfatoriamente à natureza jurídica de contrato administrativo típico, resultando na avença consensual, geralmente preventiva de litígio na qual a administração buscará a reparação do bem ambiental lesado”.

Em posicionamento contrário está Milaré (2006, p.11-12), o qual considera o compromisso de ajustamento de conduta como um mecanismo de solução pacífica de conflitos, com natureza jurídica de transação, pois estabelece certas regras de conduta a serem observadas pelo interessado e inclui a adoção de medidas destinadas à proteção do interesse difuso atingido.

Denota-se que o compromisso de ajustamento de conduta é uma garantia mínima em benefício da coletividade, o qual busca proporcionar um ambiente de negociação, visando trazer melhores resultados na conciliação entre o meio ambiente e o desenvolvimento.

Em que pese os órgáos legitimados a tomar o compromisso de ajustamento poder dispor do conteúdo processual do termo, como, por exemplo, a estipulação de prazos para cumprimento, não detêm disponibilidade sobre o direito material, haja vista que o meio ambiente pertence à coletividade como um bem jurídico indisponível (REALE, 2007, p. 302) 23 .

23 Por interesses individuais e sociais indisponíveis se entendem aqueles que, por sua natureza essencial ao valor e à sobrevivência da pessoa humana ou da coletividade, não poderão ser objeto de renúncia, de troca ou de cessăo a terceiros, ou quando a lei lhes conferir essa qualidade. 
Já Hugo Nigro Mazzili (2015a, p.104-105), por sua vez, entende que o compromisso de ajustamento de conduta não tem natureza contratual, pois os órgãos públicos que o tomam não têm poder de disposição, não podendo ser considerado transação própria, haja vista que a transação importa poder de disponibilidade, e os órgáos públicos legitimados a tomar o compromisso possuem apenas disponibilidade do conteúdo processual da lide, mas não detêm disponibilidade sobre o próprio direito material controvertido. Assim, o compromisso de ajustamento de conduta "é um ato administrativo negocial (negócio jurídico de direito público), que consubstancia uma declaração de vontade do Poder Público coincidente com a do particular causador do dano, que concorda em adequar sua conduta às exigências da lei”.

Depreende-se que o termo de ajustamento de conduta é um ajuste de conduta do investigado à lei para cumprir o que ela determina, pois, o órgão público que o toma pode apenas negociar prazos e nunca o que diz a lei.

Não obstante a divergência doutrinária existente, entende-se neste trabalho que a natureza jurídica do termo de ajustamento de conduta ambiental, posto que seja uma modalidade especial de compromisso, pode ser enquadrado como um ato administrativo negocial realizado entre o poder público e o causador do dano que concorda em adequar sua conduta às exigências legais (MAZZILI, 2015b).

A disciplina jurídica do ajustamento de conduta deve oferecer um mínimo de estabilidade e garantia ao compromissário de que se configura uma verdadeira alternativa à jurisdição. Se o autor do dano se submete ao ajuste de conduta, sujeito ainda a cominaçóes em caso de descumprimento do compromisso, há de militar-lhe um mínimo de segurança jurídica. E essa segurança consiste em não se pode desprezar a existência do compromisso, para que não haja desvalorização do instituto, conforme orientação do ilustre Rodrigo Fernandes (2008).

Não se tem dúvida, que dentre os princípios basilares do Direito Ambiental de prevenção e reparação do dano, a assinatura do referido Termo de Ajustamento de conduta é a forma mais célere e efetiva possível, em decorrência da desnecessidade da intervenção do Poder Judiciário, ou mesmo com a extinção dos processos que já tramitam, como no caso em questão; porém é importante deixar consignado que existe, sim, quando o bem jurídico tutelado é o meio ambiente a necessidade de responsabilização "judicial ou efetiva”, pois como visto, o meio ambiente mereceu "consagração constitucional especialíssima" 24 , categorizada como "direito fundamental da pessoa humana", na medida em que a destruição ambiental compromete a possibilidade de uma existência digna para os seres humanos das geraçôes não só de hoje, mas também e sobretudo as de amanhã.

24 Cf. Voto proferido pelo Ministro Carlos Alberto Menezes Direito. ADI 3378-6/DF. 
Assim, as medidas compensatórias avençadas no Termo de Ajustamento de Conduta (MPF, 2013), quais sejam: (i) a conservação da biodiversidade no litoral, (ii) o uso sustentável dos recursos pesqueiros, o fortalecimento da pesca artesanal e (iii) educação ambiental, na qual a CHEVRON BRASIL no valor total de R 95.160 .000 (noventa e cinco milhóes, cento e sessenta mil reais) tornam-se insuficientes diante da análise global do direito ambiental fundamental violado.

\section{Conclusões}

O vazamento de petróleo no Campo de Frade, na Bacia de Campos, com suas implicaçóes na ecologia e no desenvolvimento econômico nacional, faz com que as recentes descobertas de grandes reservas de hidrocarbonetos na fronteira do Pré-sal imponham uma série de novos e complexos desafios. $\mathrm{O}$ mais importante deles é a necessidade de se repensar o direito do petróleo brasileiro, visando a adoção de medidas de caráter preventivo eficientes, capazes de inibir novos acidentes ambientais.

Diante desse novo contexto, propóe-se o seguinte problema: como a empresa americana CHEVRON, operadora do CAMPO DE FRADE (RJ), tratou os desdobramentos ambientais e jurídicos causados pelo vazamento de petróleo, junto as autoridades brasileiras, com destaque a questão da competência e soberania e o papel da responsabilidade civil objetiva e suas teorias, com a extinção das duas açóes civis públicas contra ela propostas pelo Ministério Público Federal diante do Termo de Ajustamento de Conduta?

Realizou-se uma análise cronológica dos fatos que permearam os dois derramamentos de petróleo e a forma como a empresa americana Chevron lidou com o incidente e com às autoridades brasileiras. Analisou ainda, a partir dos Danos Ambientais, as consequências jurídicas causadas, discutiu-se Competência e Soberania, Responsabilidade Civil e o Termo de Ajustamento de Conduta - TAC.

Dessa forma, conforme explanado, o local do acidente foi um poço de petróleo localizado na plataforma continental brasileira. As rochas geradoras, reservatório e selante que compóe o sistema petrolífero do Campo de Frade são bens da União, cuja exploração de hidrocarbonetos foi transferida, via contrato de concessão à empresa privada Chevron, constituída sob as leis brasileiras, tal qual imposto pela Constituição da República Federativa do Brasil. Assim, mesmo existindo controvérsias sobre a questão "território marítimo", é indiscutível ser a ZEE e a Plataforma Continental brasileiras elementos geográficos integrantes do território nacional à luz da moderna legislação internacional sobre os mares.

Diante das teorias sobre o fenômeno jurídico da responsabilidade civil, na reparação e prevenção de danos ambientais decorrentes da atividade petrolífera na perspectiva da Teoria do Risco Integral, há de se ponderar que, com a assinatura do Termo de Ajustamento 
de Conduta pela Empresa Chevron, a figura jurídica da responsabilidade civil objetiva, permaneceu em segundo plano. Desta forma, partiu-se para uma irresponsabilidade objetiva em detrimento do direito econômico na continuidade das atividades de extração do petróleo.

Nesse contexto, conclui-se ainda, que a condição econômica e a influência da empresa Chevron contribuíram, em grande medida, para determinar os resultados do processo, tendo em vista que a própria ANP na condição de Agência Reguladora, interpôs recurso, junto ao Supremo Tribunal de Justiça, na forma do Agravo Regimental no 1.639 / RJ (2012/0175070-5), logrando a suspensão de liminar que a proibia de explorar novos poços no Brasil. Fato inusitado e nunca antes visto neste País em se tratando de agências reguladoras em território brasileiro.

\section{Referências}

ALONSO, Paulo Sérgio Gomes. Pressupostos da Responsabilidade Civil Objetiva. São Paulo: Saraiva, 2000.

ANP. Agência Nacional do Petróleo Gás Natural e Biocombustíveis. Investigaçáo do Incidente de Vazamento de Petróleo no Campo de Frade. Relatório Final. Superintendência de Segurança Operacional e Meio Ambiente: julho de 2012. Disponível em:< http://www.anp.gov.br/?dw=61108. $>$ Acesso em: 19/5/2015.

Agência Nacional do Petróleo Gás Natural e Biocombustíveis. Contrato de Concessáo do Campo de Frade $n^{\circ}$ 48000.003896/97-20. 2007. Disponível em: <http://www.anp.gov.br/?dw=861>. Acesso em: 19/5/2015.

BRASIL. Constituição da República Federativa Brasil. Brasília, DF: Senado, 1988. Disponível em: <http://www.planalto.gov.br/ccivil_03/constituicao/constituicaocompilado.htm>. Acesso em: 15/5/2015.

. Lei Federal $\mathrm{n}^{\circ} \mathbf{6 . 9 3 8}$, de 31 de agosto de 1981. Dispóe sobre a Política Nacional do Meio Ambiente, seus fins e mecanismos de formulação e aplicação. Disponível em: <http://www.planalto.gov.br/ccivil_03/leis/16938.htm>. Acesso em:10/5/2015.

Lei Federal $n^{\circ}$ 8.005, de 22 de março de 1990. Dispóe sobre a cobrança e a atualização dos créditos do Instituto Brasileiro do Meio Ambiente e dos Recursos Naturais Renováveis (Ibama). Disponível em: <http://www.planalto.gov.br/ccivil_03/LEIS/L8005.htm>. Acesso em: 10/5/2015.

. Lei Federal n $\mathbf{n}^{\circ} \mathbf{9 . 8 4 7}$, de 26 de outubro de 1999. Dispóe sobre a fiscalização das atividades relativas ao abastecimento nacional de combustíveis, de que trata a Lei $\mathrm{n}^{\circ}$ 9.478, de 6 de agosto de 1997, estabelece sançóes administrativas. Disponível em: <http://www.planalto.gov.br/CCivil_03/leis/L9847.htm>. Acesso em: 10/5/2015. 
. Lei Federal $\mathrm{n}^{\circ} \mathbf{8 . 6 1 7}$, de 4 de janeiro de 1993. Dispóe sobre o mar territorial, a zona contígua, a zona econômica exclusiva e a plataforma continental brasileiros. Disponível em: <http://www.planalto.gov.br/ccivil_03/leis/18617.htm>. Acesso em:10/5/2015.

. Lei Federal $n^{\circ} 7.343$, de 24 de julho de 1995. Disciplina a ação civil pública de responsabilidade por danos causados ao meio-ambiente, ao consumidor, a bens e direitos de valor artístico, estético, histórico, turístico e paisagístico (VETADO). Disponível em: <http://www.planalto.gov.br/ccivil_03/leis/17347orig.htm>. Acesso em:10/5/2015.

. Lei Federal $\mathbf{n}^{\circ}$ 9.605, de 12 de fevereiro de 1998. Dispóe sobre as sançóes penais e administrativas derivadas de condutas e atividades lesivas ao meio ambiente. Disponível em: <http:/www.planalto.gov.br/ccivil_03/leis/19605.htm>. Acesso em: 10/5/2015.

. Lei Federal no 9.966, de 28 de abril de 2000. Dispóe sobre a prevenção, o controle e a fiscalização da poluição causada por lançamento de óleo e outras substâncias nocivas ou perigosas em águas sob jurisdição nacional. Disponível em: <http://www. planalto.gov.br/CCivil_03/leis/L9966.htm>. Acesso em: 10/5/2015.

. Lei Federal no 10.406, de 10 de janeiro de 2002. Institui o Código Civil. Disponível em: <http://www.planalto.gov.br/ccivil_03/leis/2002/110406.htm>. Acesso em: 10/5/2015.

. Decreto Federal no 1.530 , de 22 de junho de 1995. Declara a entrada em vigor da Convenção das Naçóes Unidas sobre o Direito do Mar, concluída em Montego Bay, Jamaica, em 10 de dezembro de 1982. Disponível em: <http://www.planalto. gov.br/ccivil_03/decreto/1995/D1530.htm>. Acesso em: 10/5/2015.

- Decreto Federal no 4.136, de 20 de fevereiro de 2002. Dispóe sobre a especificação das sançôes aplicáveis às infraçóes às regras de prevenção, controle e fiscalização da poluição causada por lançamento de óleo e outras substâncias nocivas ou perigosas em águas sob jurisdição nacional, prevista na Lei $\mathrm{n}^{\circ} 9.966$, de 28 de abril de 2000. Disponível em: <http://www.planalto.gov.br/ccivil_03/decreto/2002/d4136. htm>. Acesso em: 10/5/2015.

. Decreto Federal no 6.514, de 22 de julho de 2008. Dispóe sobre as infrações e sanções administrativas ao meio ambiente, estabelece o processo administrativo federal para apuração destas infrações. Disponível em: <http://www.planalto.gov.br/ ccivil_03/_ato2007-2010/2008/decreto/D6514.htm> Acesso em: 19/5/2015.

. Sentença que rejeitou a denúncia contra a Chevron, Transocean e 17 pessoas físicas. 10 ${ }^{\mathrm{a}}$ Vara Federal Criminal do Rio. Processo no 0490545-96.2011.4.02.5101. Disponível em: <www.jfrj.jus.br>. Acesso em: 10/5/2015. 
Decreto Legislativo no 5 , de 1987. Aprova o texto da Convenção das Naçóes Unidas sobre Direito do Mar, concluído em Montego Bay, Jamaica, em 10 de dezembro de 1982. Disponível em: <http://www2.camara.leg.br/legin/fed/decleg/1980-1987/decretolegislativo-5-9-novembro-1987-367281-publicacaooriginal-1-pl.html>. Acesso em: 19/5/2015.

Agravo Regimental na Suspensáo de Liminar e de Sentença no 1.639/RJ(2012/0175070-5). Relator: ministro presidente do STJ. Agravante: Agência Nacional do Petróleo Gás Natural e Biocombustíveis - ANP. Procurador: Marcelo de Siqueira Freitas e outro (s). Agravado: Ministério Público Federal. Requerido: Tribunal Regional Federal da $2^{a}$ região. Decisão. Trata-se de Agravo Regimental interposto pela Agência Nacional do Petróleo Gás Natural e Biocombustíveis - ANP. Disponível em: <http://www.stj.jus.br/portal_stj/publicacao/download.wsp?tmp. arquivo=2674 $>$ Acesso em: 19/5/2015.

CAVALIERI FILHO, Sérgio. Programa de responsabilidade civil. $11^{\text {a }}$ Ed. Revisada e Ampliada São Paulo: Atlas, 2014.

CBIE. Centro Brasileiro de Infraestrutura. Produção no Pré-sal cresce 4,8\% em relação a abril. Revista TN Petróleo. Ano XIV. No 84. Especial 2012-2016. Disponível em: <http://www.tnpetroleo.com.br/media/revista/TN_Petroleo_84_Flip_1.pdf> Acesso em: 19/05/2015.

CONAMA. Resoluçáo CONAMA no 398, de 11 de junho de 2008. Revoga a Resolução no 293, de 2001. Dispóe sobre o conteúdo mínimo do Plano de Emergência Individual para incidentes de poluição por óleo em águas sob jurisdição nacional, originados em portos organizados, instalaçóes portuárias, terminais, dutos, sondas terrestres, plataformas e suas instalaçôes de apoio, refinarias, estaleiros, marinas, clubes náuticos e instalaçôes similares, e orienta a sua elaboração. Disponível em: <http://www.mma.gov.br/port/conama/legiabre.cfm?codlegi=575> Acesso em: $19 / 05 / 2015$.

DPF. Departamento de Policia Federal. Inquérito Policial no 0035/2011-13-SR/DPF/ RJ. Instaurado em: 16/11/2011 - término: 20 de dezembro de 2011. Disponível em: <http://s.conjur.com.br/dl/relatorio-inquerito-policial-chevron.pdf> Acesso em $19 / 5 / 2015$.

FERNANDES, Rodrigo. Compromisso de Ajustamento de Conduta Ambiental: Fundamentos, natureza jurídica, limites e controle jurisdicional. Rio de Janeiro: Renovar, 2008.

IBAMA. Instituto Brasileiro de Meio Ambiente. Estudo de Impacto Ambiental - EIA. Chevron. Atividade de Produção de Petróleo no Campo de Frade, Bacia de Campos. Setembro de 2006 - Rev. 00. 1/137. Disponível em: <http://siscom.ibama.gov. 
br/licenciamento_ambiental/Petroleo/Campo\%20de\%20Frade/EIA/> Acesso em: $19 / 5 / 2015$.

. Instituto Brasileiro de Meio Ambiente. Relatório de Impacto Ambiental - RIMA-Rev02. Chevron. 2007. Atividade de Produção de Petróleo no Campo de Frade, Bacia de Campos. Disponível em: <http://licenciamento.ibama.gov.br/Petroleo/ Campo\%20de\%20Frade/RIMA/RIMA\%20rev02.pdf> Acesso em: 19/5/2015.

. Instituto Brasileiro de Meio Ambiente. Plano de Emergência Individual (PEI). Chevron. 2014. Atividade de Produção de Petróleo no Campo de Frade, Bacia de Campos. Disponível em: <https://www.chevron.com.br/images/publicacao/Boletim_PCS_Frade_2014.pdf> Acesso em: 19/5/2015.

. Instituto Brasileiro de Meio Ambiente. Ibama multa Chevron por descumprimento de condicionantes ambientais. 2011-2012. Disponível em: <http://www. ibama.gov.br/publicadas/ibama-multa-chevron-por-descumprimento-de-condicionantes-ambientais>. Acesso em: 19/5/2015.

LAMY, Marcelo. Metodologia da pesquisa jurídica: técnicas de investigação, argumentação e redação. Rio de Janeiro: Elsevier, 2011.

LEITE, José Rubens Morato. Dano ambiental: do individual ao coletivo extrapatrimonial. 5a Ed. Rev. At. São Paulo: Editora Revista dos Tribunais, 2012.

LIMA, Alvino. Culpa e risco. 3a Ed. Rev. e Atual. São Paulo: Revista dos Tribunais, 1998.

MACHADO. Paulo Affonso Leme. Direito Ambiental Brasileiro. 23a Ed. São Paulo: Malheiros, 2015.

MARTINS. Eliane Maria Octaviano. Curso de Direito Marítimo. Volume I: teoria geral. 5a Ed. Barueri: Manole, 2015.

MAZZILI. Hugo Nigro. A defesa dos Direitos difusos em juízo. 28 a Ed. São Paulo: Saraiva, 2015.

b. Hugo Nigro. O inquérito Civil: investigaçóes do Ministério Público, compromissos de ajustamento e audiência. 4a Ed. São Paulo: 2015.

MILARÉ, Édis. Direito do Ambiente. 10ª. Ed. São Paulo: Editora Revista dos Tribunais, 2015.

. Édis; ARTIGAS, Priscila Santos. Compensaçáo ambiental: questóes controvertidas. Revista de Direito Ambiental, vol. 43. São Paulo: Revista dos Tribunais, jul. 2006.

MMA. Ministério do Meio Ambiente. Nota Informativa no01/12 CGPEG/DILIC/ IBAMA. Vazamento no Campo de Frade, na Bacia de Campos - Propostas de Moção do CONAMA - 05/01/2012. Disponível em: <http://www.mma.gov.br/port/ conama/processos/DC218947/ParecerIBAMA.pdf> Acesso em: 19/05/2015. 
MPF. Ministério Público Federal. Denúncia. Inquérito Policial no 0035/2011-13-SR/ DPF/RJ. Chevron. 21 de março de 2012. Disponível em: <http://s.conjur.com.br/ dl/chevron-denuncia-criminal-versao.pdf> Acesso em: 19/5/2015.

b. Ministério Público Federal. Açáo Civil Pública com Pedido de Liminar. Chevron. 02 de abril de 2012. Disponível em: <http://s.conjur.com.br/dl/acao-civil-publica-chevron-mpf.pdf> Acesso em: 19/5/2015.

. Ministério Público Federal. Termo de Ajustamento de Conduta - TAC. Chevron. 2013. Acesso em: <http://www.prrj.mpf.mp.br/institucional/mpf-na-capital/ atuacao/ajustamentos-de-conduta/tac-chevron-e-transocean/at_download/documento>. Aceso em: 20/5/2015.

PADILHA, Norma Sueli. Fundamentos Constitucionais do Direito Ambiental Brasileiro. Rio de Janeiro: Elsevier, 2010.

PASSOS DE FREITAS. Gilberto; PASSOS DE FREITAS, Vladimir. Crimes Contra a Natureza. 9a Edição. São Paulo: Revistas dos Tribunais, 2012.

PORTAL BRASIL. Inspetor da Marinha sobrevoa Campo de Frade para avaliar danos causados pela Chevron. 20/03/2012. Disponível em: <http://www.brasil.gov.br/ defesa-e-seguranca/2012/03/marinha-sobrevoa-campo-de-frade-para-verificar-vazamento-de-oleo>. Acesso em: 19/5/2015.

REALE, Miguel. Consulta sobre o Decreto n. 430/92 e o cabimento de ação civil pública para assegurar, aos aposentados e pensionistas da Previdência Social, reajuste em seus proventos. In: WALD, Arnoldo. (Coord). Aspectos polêmicos da açáo civil pública. 2a Ed. São Paulo: Saraiva, 2007.

RODRIGUES, Geisa de Assis. Ação civil pública e termo de ajustamento de conduta: teoria e prática. 3a Ed. Rio de Janeiro: Forense, 2011.

STEIGLEDER, Annelise Monteiro. Consideraçóes sobre o nexo de causalidade na responsabilidade civil por dano ao meio ambiente. In: NERY JUNIOR, Nelson; NERY, Maria de Andrade (Org.). Doutrinas Essenciais - Responsabilidade Civil Direito Ambiental, vol. VII. São Paulo: Revista dos Tribunais, 2010.

STOCO, Rui. Tratado de responsabilidade civil: doutrina e jurisprudência. 9a Ed. São Paulo: Editora Revista dos Tribunais, 2013.

VENOSA, Silvo de Salvo. Direito Civil: Responsabilidade Civil IV. 15ª Ed. São Paulo: Atlas, 2015.

VIÉGAS, Rodrigo Nuñez. PINTO, Raquel Giffoni. GARZON, Luis Fernando Novoa. Negociaçáo e acordo ambiental: $\mathrm{O}$ Termo de Ajustamento de Conduta (TAC) como forma de tratamento dos conflitos ambientais. Rio de Janeiro: Fundação Heinrich Böll, 2014. 